\title{
The effect of a proposed rehabilitation program to treat certain spinal injuries muscles
}

\author{
Ahmed Hikmat Mohammad ${ }^{1,2}$ \\ ${ }^{I}$ (Faculty of Physical education and Sport/ Pitesti University, Romania) \\ ${ }^{2}$ (Al-Mustansiriya University, Iraq)
}

\begin{abstract}
This study aimed to identify the impact of a rehabilitation program that uses therapeutic exercises to treat the injured who are suffering from injuries, spinal muscles, which includes: -

- Exercise sit on the bench and pull the top of the crossbar and delivery to the thighs light weight does not exceed $5 \mathrm{~kg}$ and repeating high)

- Aquatic exercises.

The study sample consisted of 7 patients with male and (3) patients with females who suffer from mild and moderate pain in the spine muscles, was the program applied for (6) weeks and by (3) times a week.
\end{abstract}

Keywords: the spine, muscles, accident, therapeutic exercise.

\section{Introduction}

The world has witnessed a remarkable technology development that has led to the emergence of many inventions and technologies on which human relies in daily life to provide comfort and speed. Despite the positives of these techniques, but they had a negative impact on the physical capabilities of the human being, which led to the reduction of activity and low level of physical fitness as a result of low level of movement and activity [1].Physical Education achieves an integrated and inclusive growth for all personality aspects, as it also makes an individual adaptable to the needs of the community in which he lives and achieves its desires, and helps him to fulfill his daily duties efficiently and effectively. Fitness includes physical and psychological concept, and sport preparation to achieve the supplies for the subject of sports ,so it requires to be appropriate with age so its impact affects the organs and muscles and respects the guidance and Kinesthetic consensus and mental ability during targeted training [2].In general, physical fitness is the broad base and the corner stone for sports activities in all ages, from which special physical fitness emerges in accordance with the nature of the sport of every individual in terms of kinetic direction of the organs used in performance of sport activity [3].Power is one of the important elements of fitness, and which is defined as the ability of the muscle to cope with external resistors characterized by high intensity, or are muscular - nervous system's ability to overcome the relatively high resistance through the use of body muscles [4].Bearing strength is defined as retaining muscular tension for a long period of time; and some of the sports that need this include swimming, rowing and gymnastics [3]. We can develop a rehabilitation program for spinal muscles injuries using bench exercise, pulling the bar from the top and to deliver it to the thighs with light weight that does not exceed $5 \mathrm{~kg}$ with very high repeat, and aquatic exercises to rehabilitate the spine muscles [5].

\section{Objuctive of the study}

The current study aimed at :

- There is a statistically significant effect of bench exercise and pulling the bar from the top and to deliver it to the thighs with light weight that does not exceed $5 \mathrm{~kg}$ on the spinal muscles.

- There is a statistically significant effect of aquatic exercises in the rehabilitation of spine muscles?

\section{Hypothesis of the study}

- There is no statistically significant effect of bench exercise and pulling the bar from the top and to deliver it to the thighs with light weight that does not exceed $5 \mathrm{~kg}$ on the spinal muscles.

-- There is no statistically significant effect of aquatic exercises in the rehabilitation of spine muscles.

\section{- Methodology}

In this study the researcher will use the experimental method using pretest/posttest design for both groups (experimental and control group).

- Study population

Study population will consist of athletes with backbone injuries in fitness first. 


\section{- Study sample}

Study sample will consist of athletes with backbone injuries who may be affected by the proposed rehabilitation program in fitness first.

\section{- Study variables}

Independent variable: rehabilitation program, a bench, aquatic exercises.

Dependent variable: rehabilitation of spinal muscles.

\section{- Used tools}

- $\quad$ Bench device

- Cork used in swimming

- Whistle and Weights

- Tests that are used for data collection

- Sitting on bench and pulling the bar from the top and to deliver it to the thighs with light weight that does not exceed $5 \mathrm{~kg}$.

- Aquatic exercises for the rehabilitation of spinal muscles.

\section{Rehabilitation program}

A training program is designed for (6) weeks of (3) units a week for an hour, consisting of three parts, introductory, main and a closing parts. This program is based on a set of pre-prepared exercises and appropriate for bench and Aquatic exercises, which aims to rehabilitate the injured muscles of the spine.

\section{- Introductory part}

Warm-up for a period of (5-10 minutes) Warm-up starts by jogging to raise body temperature and to make the various organs of the body especially the Circulatory and respiratory systems ready and then to extend the period from (2-5 minutes) of the muscles involved.

\section{- Main part}

Pulling the bar from the top and to deliver it to the thighs with light weight that does not exceed $5 \mathrm{~kg}$ with very high repeat. Exercise duration was (20-30 minutes) for each participant and Aquatic exercises will be using Cork for the rehabilitation of spinal muscles.

\section{- Closing part}

Gradual reduction of the intensity to reach the state that was before the training unit or near it, recovery operations help to achieve its objectives and duration of this part is (5-10 minutes).

\section{- Methodology}

The researcher used the quasi-experimental approach, which fits with the objectives of the current study, which is to identify the rehabilitation program for injured spinal muscles.

\section{- Study design and variables}

Accordingly, the researcher has applied a quasi-experimental design to two experimental and control groups as follows:

$$
\begin{array}{llll}
02 & \mathrm{X} & 01 & \mathrm{R}
\end{array}
$$

Interpretation of the table symbols:

R: Randomization

$\mathrm{X}$ : Experimental treatment through the rehabilitation program

01: pretest

02: posttest

\section{- Statistical methods}

In order to answer the hypotheses of the study the following statistical methods were used:

1. Means and standard deviations.

2. Covariance analysis.

- $\quad$ Statistical methods

- Extract the frequencies and percentages to describe the study sample.

- Means and standard deviations.

- The use of $t$-test to identify differences in the injuries of muscles of the spine before and after rehabilitation program. 


\section{Results Analysis}

This chapter provides an overview of the findings of the study, which aimed to identify the impact of rehabilitation program for spinal muscles injuries.The following are the results of the current study.

The first question: (What are the characteristics of the study sample individuals who suffer from spinal muscles injuries?). In order to identify the characteristics of the study sample individuals who suffer from spinal muscles injuries frequencies and percentages for the distribution of the study sample by sex and weight were calculated.

Table (1) the distribution of the study sample by sex and weight

\begin{tabular}{|c|c|c|}
\hline Sex & Frequency & Percentage \\
\hline Male & 7 & 70.0 \\
\hline Female & 3 & 30.0 \\
\hline Total & 10 & 100.0 \\
\hline
\end{tabular}

Table (2) the distribution of the study sample by weight

\begin{tabular}{|c|c|c|}
\hline Weight & Frequency & Percentage \\
\hline Less than 60 kg & 1 & 10.0 \\
\hline 60-80 kg & 7 & 70.0 \\
\hline More than 80 kg & 2 & 20.0 \\
\hline Total & 10 & 100.0 \\
\hline
\end{tabular}

The first question: are there statistically significant differences at the significance level $\alpha(\alpha \geq 0,05)$ between the averages of the frequencies of bench exercise, pulling the bar from the top and to deliver it to the thighs before and after the rehabilitation program to alleviate the spinal muscles injuries?

To identify the frequencies of bench exercise, pulling the bar from the top and to deliver it to the thighs before and after the rehabilitation program to alleviate the spinal muscles injuries, means were calculated as shown in table (3) below:

Table (3): Bench exercise, pulling the bar from the top and to deliver it to the thighs with light weight that does not exceed $5 \mathrm{~kg}$ for 10 athletes.

\begin{tabular}{|c|c|c|}
\hline \multicolumn{3}{|c|}{$\begin{array}{l}\text { Bench exercise, pulling the bar from the top and to deliver it to the thighs with light weight } \\
\text { that does not exceed } 5 \mathrm{~kg} \text { for one month }\end{array}$} \\
\hline Day & $\begin{array}{l}\text { Frequency before the } \\
\text { program / } 5 \text { minutes }\end{array}$ & $\begin{array}{l}\text { Frequency after the program / } 5 \\
\text { minutes }\end{array}$ \\
\hline 1 & 12.3 & 25.6 \\
\hline 2 & 10.1 & 30.4 \\
\hline 3 & 13.2 & 34.4 \\
\hline 4 & 8.1 & 35.1 \\
\hline 5 & 8.5 & 36.8 \\
\hline 6 & 10.4 & 37.4 \\
\hline 7 & 10.2 & 38.7 \\
\hline 8 & 10.4 & 32.1 \\
\hline 9 & 12.4 & 33.4 \\
\hline 10 & 13.5 & 34.5 \\
\hline 11 & 12.1 & 34.6 \\
\hline 12 & 11.2 & 33.4 \\
\hline 13 & 14.3 & 34.7 \\
\hline 14 & 15.6 & 35.5 \\
\hline 15 & 10.4 & 36.0 \\
\hline 16 & 12.6 & 32.0 \\
\hline 17 & 13.6 & 33.0 \\
\hline 18 & 11.7 & 31.7 \\
\hline 19 & 10.4 & 32.4 \\
\hline 20 & 10.4 & 33.6 \\
\hline 21 & 12.4 & 34.4 \\
\hline 22 & 13.4 & 35.5 \\
\hline 23 & 14.1 & 35.5 \\
\hline 24 & 12.9 & 35.5 \\
\hline 25 & 12.8 & 35.9 \\
\hline 26 & 12.0 & 35.6 \\
\hline 27 & 14.0 & 36.4 \\
\hline 28 & 13.2 & 36.3 \\
\hline 29 & 11.0 & 36.4 \\
\hline 30 & 12.5 & 36.4 \\
\hline total & 11.99 & 34.44 \\
\hline
\end{tabular}


The results of table (3) showed that the average of the frequency of pulling the bar from the top and to deliver it to the thighs before the program (11.99) for each 5 minutes and for 10 athletes for 30 readings for a period of one month. The results of table (2) showed that the average of the frequency of Pulling the bar from the top and to deliver it to the thighs after the program(34.44) for each 5 minutes and for 10 athletes for 30 readings for a period of one month. In order to identify the significance of differences in the level of frequencies before and after the program, Paired Sample T-test was used, and the results appear in the table (3) as follows:

Tables (4): Paired Sample T-test to identify the significance of differences in the level of frequencies before and after the program (the average of the frequency of Pulling the bar from the top and to deliver it to the thighs before the program)

\begin{tabular}{|c|c|c|c|c|c|c|c|c|c|c|}
\hline \multicolumn{8}{|c|}{ Paired Samples Statistics } & & & \\
\hline & & Mean & \begin{tabular}{l|l}
$\mathrm{N}$ & \\
\end{tabular} & Std. Deviat & & Std. & ror Mean & & & \\
\hline \multirow[t]{2}{*}{ Pair 1} & before & 11.9900 & 30 & & 1.73828 & & .31737 & & & \\
\hline & after & 34.4400 & 30 & & 2.49767 & & .45601 & & & \\
\hline \multicolumn{8}{|c|}{ Paired Samples Correlations } & & & \\
\hline & & & $\mathrm{N}$ & Correlati & & & ig. & & & \\
\hline Pair 1 & \multicolumn{2}{|c|}{ before \& after } & 30 & & .005 & & .981 & & & \\
\hline \multicolumn{11}{|c|}{ Paired Samples Test } \\
\hline & & \multicolumn{6}{|c|}{ Paired Differences } & $\mathrm{t}$ & $\mathrm{df}$ & Sig. (2- \\
\hline & & \multirow[t]{2}{*}{ Mean } & $\begin{array}{c}\text { Std. } \\
\text { Deviation }\end{array}$ & \multirow[t]{2}{*}{$\begin{array}{l}\text { Std. Error } \\
\text { Mean }\end{array}$} & \multicolumn{3}{|c|}{$\begin{array}{l}\text { 95\% Confidence Interval of the } \\
\text { Difference }\end{array}$} & & & tailed) \\
\hline & & & & & \multicolumn{2}{|c|}{ Lower } & Upper & & & \\
\hline Pair 1 & $\begin{array}{l}\text { before - } \\
\text { after }\end{array}$ & $-2.24500 \mathrm{E} 1$ & 3.03653 & .55439 & \multicolumn{2}{|c|}{$-23.58386-$} & $-21.31614-$ & $-40.495-$ & 29 & .000 \\
\hline
\end{tabular}

The second question: are there statistically significant differences at the significance level $\alpha(\alpha \geq 0,05)$ between the averages of the frequencies of Aquatic exercises using Cork to alleviate the spinal muscles injuries? In order to identify the frequencies of Aquatic exercises using Cork before and after the program to alleviate the spinal muscles injuries means were calculated as shown in table (5) below:

Table (5): frequencies of Aquatic exercises using Cork to alleviate the spinal muscles injuries before and after the program for 10 athletes.

\begin{tabular}{|c|c|c|}
\hline Day & $\begin{array}{l}\text { Frequency before } \\
\text { the program / } 5 \text { minutes }\end{array}$ & $\begin{array}{l}\text { Frequency after the } \\
\text { program / } 5 \text { minutes }\end{array}$ \\
\hline 1 & 20.2 & 40.0 \\
\hline 2 & 24.4 & 40.5 \\
\hline 3 & 23.2 & 42.6 \\
\hline 4 & 24.4 & 42.1 \\
\hline 5 & 25.4 & 42.5 \\
\hline 6 & 25.6 & 41.1 \\
\hline 7 & 25.5 & 40.0 \\
\hline 8 & 24.5 & 40.0 \\
\hline 9 & 25.5 & 44.2 \\
\hline 10 & 25.4 & 42.3 \\
\hline 11 & 26.4 & 42.5 \\
\hline 12 & 24.6 & 41.5 \\
\hline 13 & 25.4 & 44.1 \\
\hline 14 & 25.5 & 46.0 \\
\hline 15 & 22.4 & 45.5 \\
\hline 16 & 20.4 & 45.3 \\
\hline 17 & 22.2 & 45.0 \\
\hline 18 & 24.3 & 42.1 \\
\hline 19 & 23.4 & 42.5 \\
\hline 20 & 21.4 & 41.1 \\
\hline 21 & 21.4 & 40.0 \\
\hline 22 & 24.4 & 40.0 \\
\hline 23 & 22.4 & 44.2 \\
\hline 24 & 23.4 & 42.3 \\
\hline 25 & 22.5 & 42.5 \\
\hline 26 & 24.5 & 41.5 \\
\hline 27 & 21.5 & 44.1 \\
\hline 28 & 22.6 & 46.0 \\
\hline 29 & 23.5 & 42.1 \\
\hline 30 & 22.5 & 42.5 \\
\hline Total & 23.63 & 42.54 \\
\hline
\end{tabular}


The results of table (5) showed that the frequencies of Aquatic exercises using Cork to alleviate the spinal muscles injuries before the program (23.63) for each 5 minutes, for 10 athletes for 30 readings for a period of one month. The results of table (4) showed that the frequencies of Aquatic exercises using Cork to alleviate the spinal muscles injuries after the program (42.54) for each 5 minutes, for 10 athletes for 30 readings for a period of one month. In order to identify the significance of differences in the level of frequencies before and after the program, Paired Sample T-test was used, and the results appear in the table (6) as follows:

Tables (6): Paired Sample T-test to identify the significance of differences in the level of frequencies before and after the program (frequencies of Aquatic exercises using Cork to alleviate the spinal muscles injuries before and after the program).

\begin{tabular}{|c|c|c|c|c|c|c|c|c|c|c|}
\hline \multicolumn{9}{|c|}{ Paired Samples Statistics } & & \\
\hline & & \multicolumn{2}{|l|}{ Mean } & $\mathrm{N}$ & \multicolumn{2}{|c|}{ Std. Deviation } & \multicolumn{2}{|c|}{ Std. Error Mean } & & \\
\hline \multirow[t]{2}{*}{ Pair 1} & befor1 & 23.6267 & & 3 & & 1.67948 & \multicolumn{2}{|c|}{.30663} & & \\
\hline & After1 & 42.5367 & & 3 & & 1.85871 & \multicolumn{2}{|c|}{.33935} & & \\
\hline \multicolumn{9}{|c|}{ Paired Samples Correlations } & & \\
\hline & & & & \multicolumn{3}{|c|}{ Correlation } & \multicolumn{2}{|c|}{ Sig. } & & \\
\hline Pair 1 & \multicolumn{2}{|c|}{ befor1 \& After1 } & & & & $.126-$ & \multicolumn{2}{|l|}{.508} & & \\
\hline \multicolumn{11}{|c|}{ Paired Samples Test } \\
\hline & & \multicolumn{6}{|c|}{ Paired Differences } & & \multirow{3}{*}{$\mathrm{f}$} & Sig. (2- \\
\hline & & \multirow[t]{2}{*}{ Mean } & \multirow[t]{2}{*}{$\begin{array}{l}\text { Std. } \\
\text { Deviation }\end{array}$} & \multirow{2}{*}{\multicolumn{2}{|c|}{$\begin{array}{l}\text { Std. Error } \\
\text { Mean }\end{array}$}} & \multicolumn{2}{|c|}{$\begin{array}{l}95 \% \text { Confidence } \\
\text { Interval of the Difference }\end{array}$} & & & tailed) \\
\hline & & & & & & Lower & Upper & & & \\
\hline Pair 1 & $\begin{array}{l}\text { befor1 - } \\
\text { After1 }\end{array}$ & $\begin{array}{l}- \\
1.89100 \mathrm{E} \\
1\end{array}$ & 2.65698 & .485 & & $-19.90213-$ & $-17.91787-$ & $-38.982-$ & 2 & .000 \\
\hline
\end{tabular}

The results of tables (6) show the existence of statistically significant differences at the significance level (0.05) and less, where the mean of the average of frequencies before the program was (23.63) and after the program (42.54) while $t$ value was (38.982-) which is statistically significant at the significance level (0.05) what indicates that the program is effective and reduces the spinal muscles injuries.

\section{Conclusion}

The results show the existence of statistically significant differences at the significance level (0.05) and less, using bench exercise, pulling the bar from the top and to deliver it to the thighs with light weight that does not exceed $5 \mathrm{~kg}$ with very high repeat. The results show the existence of statistically significant differences at the significance level (0.05) using aquatic exercises to rehabilitate the spine muscles.

\section{Acknowledgements}

The author would like to acknowledge the financial support of the Ph.D. studies by the Iraqi Ministry of Higher Education and Scientific Research.

\section{References}

[1] Bani Melhem, the impact of some exercises on some physical oxygenic and non- oxygenic abilities and physiological changes among Yarmouk University ,Najah University Journal for Research (Humanities), Vol (26), number (1), (p. 106).

[2] Hussein, Hassan and Qasim Al-Anbaki, Mansour Jamil, , fitness and ways to achieve it, Baghdad: The Ministry of Higher Education and Scientific Research(1988).

[3] Rabadi, Kamal Jamil, the athletic training of the twentieth century, University of Jordan, (2004).

[4] Al- Anzi, Ghazi ,elements of fitness: speed, strength, fitness, flexibility, endurance, balance, compatibility, physical education library, (2009).

[5] N. Burns, Suspension Training: How Risky Is It? New York times article, available at: http://www.nytimes.com/2007/02/01/fashion/01 fitness.html/r=1,(2007), 